\title{
FUNGSI PAWON SEBAGAI DESAIN PEROLEHAN PANAS PADA HUNIAN DI DAERAH DINGIN
}

\author{
Gaguk Sukowiyono \\ Dosen Prodi Arsitektur, Fak. Teknik Sipil dan Perencanaan, ITN Malang \\ e-mail: gaguksukowiyono@yahoo.com \\ Debby Budi Susanti \\ Dosen Prodi Arsitektur, Fak. Teknik Sipil dan Perencanaan, ITN Malang \\ e-mail: budisusantidebby@gmail.com
}

\begin{abstract}
ABSTRAK
Pawon adalah dapur bagi masyarakat Jawa yang berupa tempat memasak yang menggunakan tungku sebagai pembakaran dengan kayu sebagai bahan bakarnya dan menghasilkan abu (awu) sepanjang hari. Pawon pada jaman dahulu dikenal sebagai daerah privat bagi kaum wanita dan merupakan area yang tabu bagi kaum pria. Karena pawon juga kerap menjadi tempat berkumpul wanita penghuni rumah dengan kaum wanita di lingkungan sekitar rumahnya.Saat ini di beberapa desa bisa ditemui pawon yang sudah beralih fungsi. Tidak hanya sekedar sebagai tempat memasak bagi kaum wanita saja, tetapi juga sebagai tempat berkumpul dan pusat aktifitas bagi seluruh penghuni rumah. Mereka terbiasa berkumpul, berinteraksi dan melakukan sebagian besar aktifitasnya selama berada di rumah di dalam ruang pawon. Mereka juga terbiasa menerima tamu dan berinteraksi dengan orang-orang di lingkungan sekitarnya di dalam ruang pawon. Perapian yang terletak pada ruang pawon dapat dijadikan sebagai salah satu konsep yang relevan dalam peningkatan suhu udara di dalam bangunan. Model perapian dan besaran api penghasil panas sangat menentukan dalam terwujudnya tingkat kenyamanan.
\end{abstract}

\section{Kata kunci : pawon, kenyamanan thermal, kondisi lingkungan}

\begin{abstract}
Pawon is a kitchen for the Java community in the form of a cooking place that uses a furnace as wood burning as fuel and produce ash (awu) throughout the day. Pawon in antiquity is known as a private area for women and is a taboo area for men. Because the pawon is also often a gathering place for women inhabitants of the house with the women in the neighborhood around his house.Currently in some villages can be found pawon who have switched functions. Not just as a place to cook for women only, but also as a gathering place and activity center for all residents of the house. They are used to gathering, interacting and doing most of their activities while at home in the pawon room. They are also accustomed to receiving guests and interacting with people in the surrounding environment inside the pawon room. Fireplaces located in the pawon space can serve as one of the relevant concepts in increasing the air temperature inside the building. Fireplace model and heat-generating fire quantity are crucial in the realization of comfort level.
\end{abstract}

PAWON: Jurnal Arsitektur, Nomor 01 Volume II, Bulan Januari-Juni Tahun 2018, ISSN 2597-7636 


\section{Keywords : pawon, thermal comfort, environmental conditions}

\section{PENDAHULUAN}

Pawon atau dapur merupakan salah satu bagian ruang dalam sebuah hunian yang keberadaannya tidak bisa dihilangkan begitu saja. Bahkan saat ini, ada hunian yang sudah menggunakan dua buah dapur, yaitu dapur bersih dan dapur kotor. Pada masa lampau, keberadaan pawon identik dengan daerah yang kotor dan menyimbolkan dengan salah satu gender, yaitu wanita (Nainggolan, 2013).Sehingga tidak heran jika ada yang berpendapat bahwa pawon atau dapur harus ditempatkan pada daerah yang tersembunyi dan tidak nampak secara langsung dari luar. (Rohmah, 2013).Pada kajian Arsitektur Jawa, pawon biasanya menempati area servis yang letaknya di belakang. Hal ini disebabkan karena fungsi pawon sebagai tempat memasak dan menyiapkan makanan. Pawon dalam bahasa Jawa berasal dari kata 'awu', yang berarti tempat atau ruangan untuk tempat memasak yang menggunakan kayu sebagai bahan bakarnya dan selalu menghasilkan awu. (Prijotomo, 1999)

Dalam kenyataannya saat ini, posisi pawon tidaklah selalu diletakkan pada posisi belakang rumah, yang hanya bisa diakses oleh kaum wanita saja. Tetapi pawon pada Arsitektur Jawa saat ini ada yang diletakkan pada daerah yang langsung bisa diakses dari arah pintu masuk hunian, walaupun ada juga yang masih terpisah dari rumah induk. Pawon tersebut tetap dapat diakses oleh seluruh penghuni rumah, bahkan tak jarang mereka juga menerima tamu di area pawon tersebut. (Nainggolan, 2013). Perubahan konsep dapur/pawon yang tadinya tertutup closed space menjadi opened space memiliki manfaat yaitu dapat menimbulkan interaksi dan komunikasi terhadap penghuninya. (Derwentyana, 2011)

Pawon juga merupakan tempat menghangatkan tubuh, tempat ritual adat dan tempat berkumpul atau bersosialisasi. (Nuryanto : 2009, 2011). Menurut Sumintarsih:2010, Pawon adalah bangunan yang khusus disediakan untuk kegiatan memasak dan memiliki tungku. Nainggolan (2013) memberikan pengertian pawon berdasarkan piranti yang ada di dalamnya, yaitu dapur di Jawa adalah tempat yang terdiri dari rak, perapian atau tungku, dan meja kursi untuk makan. Dapur adalah tempat memasak yang mempunyai tungku besar dan tempat membuat batu bata (Kamus Besar Bahasa Indonesia). Fungsi yang agak berbeda diberikan oleh Arfianti : 2005, pawon adalah tempat memasak, menjahit, membatik, mencuci, menyetrika.

Dari beberapa kajian tentang pengertian pawon tersebut dapat diambil kesimpulan bahwa yang dimaksud dengan istilah pawon (berasal dari kata awu) adalah tempat memasak yang memiliki tungku yang menggunakan

PAWON: Jurnal Arsitektur, Nomor 01 Volume II, Bulan Januari-Juni Tahun 2018, ISSN 2597-7636 
bahan bakar kayu dan tidak disadari secara langsung bahwa ada hawa panas yang keluar dengan kekuatan tertentu (tergantung bahan bakar yang digunakan) dari pawon.

\section{TINJAUAN PUSTAKA}

Pemaknaan pawon yang lebih luas dan tidak hanya sekedar sebagai tempat memasak disampaikan oleh Nuryanto : 2009, 2011, yang mengatakan pawon adalah tempat memasak, tempat menghangatkan tubuh, tempat ritual adat dan tempat berkumpul atau bersosialisasi. Pada pengertian tentang fungsi pawon tersebut menandakan bahwa pawon saat ini tidak hanya sekedar tempat memasak atau menyiapkan makanan saja tetapi juga bisa dijadikan tempat bersosialisasi antara penghuni rumah maupun antara penghuni rumah dengan orang yang berada di sekitar lingkungan rumah. Tungku yang identik dengan pawon dapat dijadikan daya tarik bagi penghuni rumah untuk berkumpul bersama menghangatkan tubuh dalam ruang pawon.

\subsection{Kajian Tentang Pawon Dan Kebudayaan}

Dapur, dalam bahasa Jawa disebut pawon, mangandung dua pengertian; pertama, bangunan rumah yang khusus disediakan untuk kegiatan masak-memasak, dan; kedua, dapat diartikan tungku. Kata pawon berasal dari kata dasar awu yang berasal dari kata dasar awu yang berarti abu, mendapatkan awalan pa dan akhiran an, yang berarti tempat. Dengan demikian, pawon (pa+awu+an) yang berarti tempat awu atau abu (Sumintarsih dalam Jurnal Jantra, Juni 2006:18).

Konsep tata ruang dalam seperti rumah di Jawa umumnya yang menganggap bagian dalam rumah adalah sesuatu yang privat, memasuki rumah, bagian depan rumah yaitu bale (bersifat publik, profan dan cahaya cukup terang). Pada bagian lebih dalam yaitu jrumah atau inti rumah, bagian ini hanya bisa diakses oleh penghuni dan kerabat karena sifatnya privat atau orang lain dengan seizin pemilik. Ruang ini gelap tanpa ada pencahayaan alami. Selanjutnya adalah pawon atau dapur dengan sifat ruang servis atau semiprivat, cahaya bisa masuk pada pintu belakang sehingga cukup terang.

Pawon bisa menjadi area penting bagi sosial. ketika mempunyai hajatan atau selametan, maka para keluarga atau tetangga (rewang) akan berkumpul untuk memasak. Interaksi komunikatif dengan lebih dari satu orang, berbagai pembicaraan meskipun hanya sekedar basa-basi, menjadi warna tersendiri bagi kaum wanita (wadon). Di pawon itulah terjadi komunikasi aktif, saat kaum wanita (wadon) sedang rewang. sehingga mayoritas pawon yang terdapat di desa Pandansari berukuran cukup luas.

PAWON: Jurnal Arsitektur, Nomor 01 Volume II, Bulan Januari-Juni Tahun 2018, ISSN 2597-7636 
Jika pemilik cukup kaya, ada ruang transisi antara rumah dan pawon yaitu pendopo yang fungsinya seperti ruang keluarga. Ruang dalam juga menganut prinsip dualitas dan sentralitas. Disebut dualitas karena adanya keterpasangan yang saling berlawanan seperti yang diungkapkan oleh LeviStrauss dalam Waterson (1997) yaitu zona laki-laki-perempuan.

\subsection{Iklim Tropis Lembab}

Lokasi penelitian ini berada di wilayah Indonesia yang secara umum memiliki iklim tropis lembab. Karakteristik iklim tropis lembab mempunyai derajat kelembaban dan curah hujan yang tinggi. Dampak dari kondisi tersebut adalah banyak terdapat bukaan dan naungan berupa sosoran. Sepanjang tahun mempunyai temperatur rata-rata yang tinggi, sehingga memepengaruhi bangunan mempunyai bukaan yang mempertimbangkan aliran udara. Kondisi tersebut berhubungan dengan diurnal yang rendah sekitar 8 derajat Celsius, akibat variasi temperatur yang rendah. Radiasi matahari bervariasi dengan kondisi sering berawan.

Tujuan dari perancangan di daerah tropis lembab adalah mereduksi temperatur internal, memaksimalkan ventilasi untuk efektifitas evaporasi, proteksi terhadap sinar matahari, hujan dan serangga. Suhu udara yang relatif panas, kelembaban udara yang tinggi, intesitas radiasi matahari yang tinggi, dan pergerakan angin yang lambat, serta curah hujan yang tinggi menjadikan kondisi iklim tropis lembab sebagai kondisi yang sulit untuk diselesaikan secara arsitektural untuk mendapatkan kondisi nyaman dalam bangunan (Szokolay, 1981).

Karakteristik utama pada iklim tropis lembab menurut Evans (1980) antara lain mempunyai fluktuasi suhu udara rata-rata harian dan tahunan relatif kecil. Dengan tidak adanya perbedaan yang signifikan pada suhu udara dan kelembaban udara pada dua musim dan dua waktu (siang dangan malam), menjadikan kondisi lingkungan sepanjang hari tidak nyaman (discomfort). Hal ini berakibat pada proses evaporasi (berkeringat) pada permukaan kulit tubuh manusia yang tidak mudah dihapus karena tingginya suhu udara dan kelembaban udara yang terjadi akibat tingginya intensitas radiasi matahari yang disertai dengan kondisi langit yang berawan sepanjang tahun.

\subsection{Kondisi Thermal Bangunan}

Kondisi termal dalam bangunan ditentukan oleh kinerja termal dari bangunan dan kondisi iklim. Kondisi tersebut disebabkan oleh adanya perpindahan panas di antara keduanya untuk mencapai kondisi yang 
seimbang (heat balance), sedangkan hantaran termal antara bangunan dengan lingkungan tergantung pada sifat panas dari material bangunan.

Wilayah Indonesia sendiri menurut Lippsmeier, berada pada zona warm-humid climate dengan sub zona equatorial rain forest climate. Zona ini memiliki kelembaban relatif $(\mathrm{RH})$ yang sangat tinggi (bisa mencapai $90 \%$ ), dengan curah hujan cukup banyak. Rata-rata suhu tahunan umumnya berkisar $23^{\circ} \mathrm{C}$ dan dapat naik sampai $38^{\circ} \mathrm{C}$ pada musim panas.

Faktor-faktor yang mempengaruhi kenyamanan termal bangunan antara lain : temperatur udara, kelembaban udara, kecepatan angin, insulasi pakaian, dan aktivitas. 


\subsection{Kenyamanan Termal}

Kondisi nyaman menurut ASHRAE, adalah kenyamanan termal seseorang yang mengekspresikan kepuasan terhadap lingkungan termal, yang dalam konteks sensasi digambarkan sebagai kondisi dimana seseorang tidak merasakan kepanasan maupun kedinginan pada lingkungan tertentu. Faktor-faktor yang mempengaruhi menurut Allard (1998) adalah lingkungan secara fisik (physical environment) dan non-fisik (non- physical environment). Sedangkan kenyamanan yang dipengaruhi lingkungan non-fisik menurut McMullan (1992) dan Allard (1998) banyak dipengaruhi oleh aktivitas yang dilakukan, jenis pakaian yang dikenakan, faktor usia, dan jenis seks. Sementara berdasarkan Santosa (1986) kenyamanan yang dipengaruhi lingkungan non-fisik pada daerah tropis lembab banyak dipengaruhi oleh aktivitas yang dilakukan dan jenis pakaian yang dikenakan.

Dalam mencapai kenyamanan termal yang lebih baik, menurut Fisk (1981) diduga manusia membentuk adaptasi dan transformasi pada lingkungannya secara tidak sadar, berdasarkan pengalamannya terhadap panas. Sehingga dalam mencapai kenyamanan manusia akan berupaya melakukan aktivitas di dalam ruang atau mencari tempat yang memungkinkan untuk memperoleh kenyamanan, dimana panas tidak dirasakan. Dengan kata lain bahwa upaya dalam mencapai kenyamanan pada akhirnya akan dilakukan sendiri oleh manusia yang merujuk pada pembentukan ruang (spatiol formation) yang mempertemukan fisik (lingkungan dan bangunan) dan non-fisik (jenis pakaian, aktivitas, budaya merespon kondisi iklim) seperti yang dikemukakan McIntyre (1980) dan Santosa (1986) yang menggambarkan keterkaitan antara aspek fisik dan aspek sosio-kultural dalam pembentukan kenyamanan termal.

\section{METODE PENELITIAN}

\subsection{Gambaran Umum Lokasi Penelitian}

Lokasi penelitian ini berada di Desa Pandansari Kecamatan Poncokusumo Kabupaten Malang yang berada di ketinggian $\pm 600-1200 \mathrm{~m}$ di atas permukaan laut dengan curah hujan rata-rata $2300-2500 \mathrm{~mm}$ per tahun dengan suhu rata-rata $21,7^{\circ} \mathrm{C}$. Hal ini menggambarkan bahwa kondisi lingkungan daerah tersebut berhawa dingin sehingga sangat berpengaruh terhadap kenyamanan rumah tinggalnya.

Mayoritas penduduk Desa Pandansari bermatapencaharian sebagai petani dan home industri. Berbagai tanaman di tanam di depan rumah penduduk desa seperti, tomat, kembang kol, kubis, apel, cabe dan lain

PAWON: Jurnal Arsitektur, Nomor 01 Volume II, Bulan Januari-Juni Tahun 2018, ISSN 2597-7636 
sebagainya.Tak hanya itu, masyarakat desa juga membuat kerajinan home industri seperti kripik singkong, kripik talas, entong dan tusuk sate serta yang lainnya. Desa Pandansari disebut sebagai desa agropolitan memiliki pemandangan yang indah dan hawa yang sejuk.

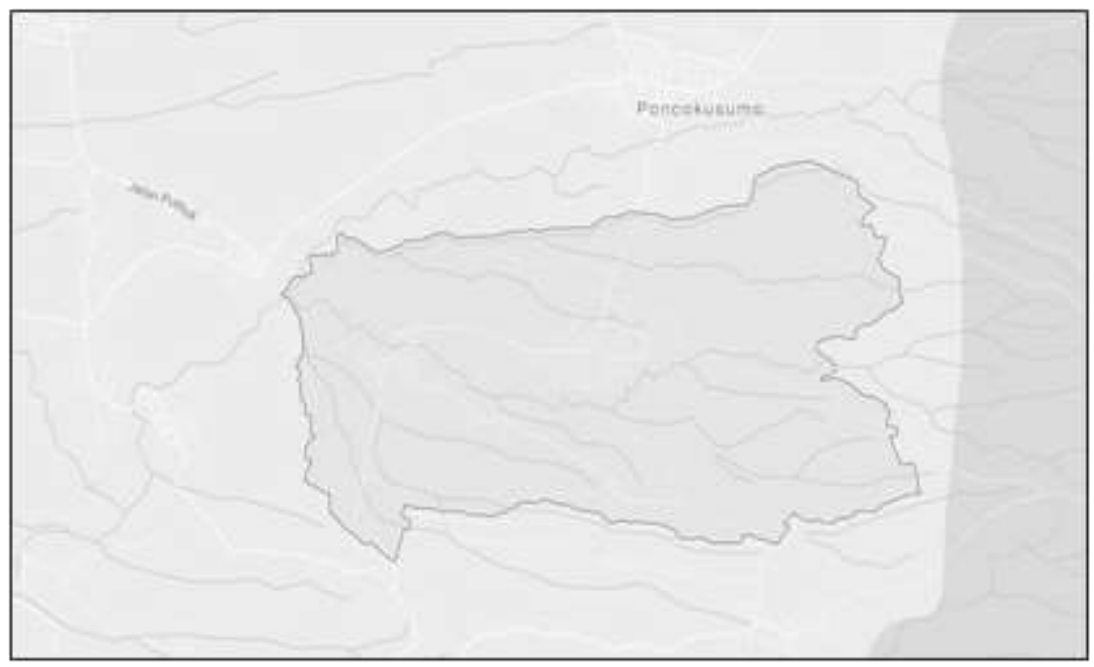

Gambar 1. Peta Desa Pandansari
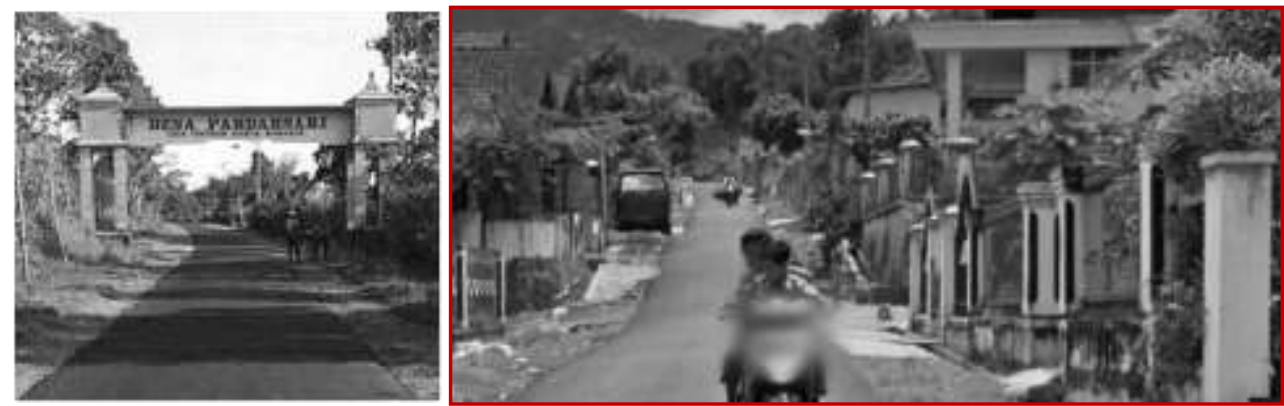

Gambar 2. Kondisi Desa Pandansari

\subsection{Metode Pengumpulan Data}

Data dibedakan menjadi 2 (dua), yaitu : data primer dan data sekunder. Data primer adalah data yang diperoleh langsung di lapangan, sedangkan data sekunder adalah data yang melengkapi data primer, yaitu yang diperoleh dari instansi terkait berupa buku/dokumen/catatan yang diteliti atau suatu hasil penelitian. 
Untuk mendapatkan data yang tepat dan dapat mendukung proses analisis, maka ada beberapa hal yang perlu diperhatikan dalam pengambilan data, yaitu : menentukan faktor pengaruh, menentukan jenis data apa yang dibutuhkan, menentukan sumber-sumber data yang relevan, menentukan cara mendapatkan data dan alat yang digunakan untuk mendapatkan data tersebut.

Bahan yang dikumpulkan dan selanjutnya digunakan dalam melakukan penelitian ini adalah sebagai berikut:

Sketsa perkembangan denah rumah. Ini digunakan untuk mengetahui ada atau tidaknya perubahan dan perkembangan penataan pawon dalam sebuah hunian.

- $\quad$ Sketsa interior pawon. Ini digunakan untuk mengetahui hal-hal apa saja yang kemungkinan menjadi daya tarik pawon untuk dijadikan sebagai ruang berinteraksi bersama penghuni rumah.

Wawancara dengan pemilik rumah. Hal ini dipergunakan untuk mengetahui historis dari hunian, mulai awal didirikan sampai dengan kondisi yang ada saat ini. Juga untuk mengetahui pola aktifitas rutin yang dilakukan penghuni rumah selama berada di pawon

Tahap selanjutnya adalah mengambil kesimpulan bagaimana peran dan fungsi pawon dalam membantu menyediakan kenyamanan thermal dalam sebuah hunian.

\subsection{Waktu Pengukuran}

Pengukuran lapangan dan perekaman kondisi lingkungan dilakukan pada obyek kasus amatan secara berkala dalam 24 jam, Pengukuran dilakukan saat aktivitas pawon berlangsung, baik pada saat pagi hari, siang hari, maupun malam hari. Aktivitas yang dilakukan adalah aktivitas seharihari yang dilakukan oleh penghunimya, baik memasak, makan, dan atau berkumpul keluarga.

\section{HASIL DAN PEMBAHASAN}

\subsection{Penggunaan Pawon}

Berdasarkan hasil pengamatan lapangan yang telah dilakukan kegiatan warga pada pawon sangatlah bervariasi. Mulai dari kegiatan masak memasak hingga berkumpul. Kegiatan masak memasak memang sangatlah lazim dilakukan seluruh warga. Kegiatan memasak warga biasa dilakukan pada pagi hari sebelum mereka berangkat menuju ladang, kegiatan memasak lainnya yaitu, menghangatkan makanan hingga memasak air 
yang biasa digunakan untuk menghangatkan air minum untuk ternak warga seperti sapi, juga lazim dilakukan warga. Kegitan lainnya seperti berkumpul untuk makan maupun saling bercengkrama juga biasa dilakukan, bagi segelintir warga. Beberapa koresponden kami menyatakan benar jika wilayah pawon mereka sering dijadikan sebagai area berkumpul. Alasan yang mendasari pawon tersebut menjadi pusat berkumpul ialah karena luas dari pawon tersebut. Selain itu berkumpul dengan tujuan unutk menghangatkan diri juga biasa dilakukan oleh beberapa warga dusun ini.
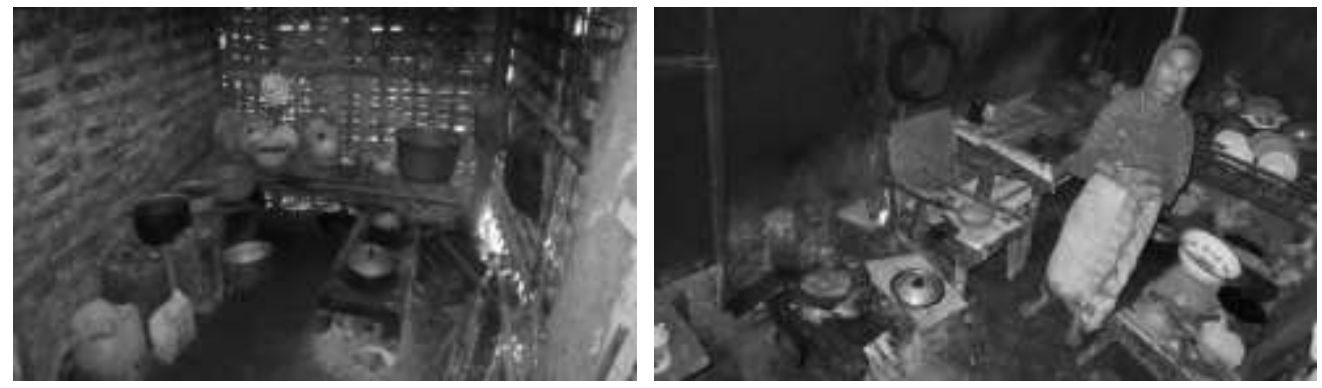

Gambar 3. Kondisi Pawon Responden

\subsection{Kondisi Iklim Dan Cuaca}

Desa Pandansari yang terletak di sebelah barat lereng Gunung Semeru memiliki suhu lingkungan yang sejuk. Suhu rata-rata desa tersebut adalah $21,7^{\circ} \mathrm{C}$. Observasi terhadap capaian suhu Desa Pandansari juga telah dilakukan dengan menilai titik-titik capaian suhu di jam-jam tertentu selama satu minggu.

Suhu pada Desa Pandansari memilki perbedaan karakteristik setiap waktunya namun memiliki rentang suhu yang cenderung sama setiap harinya, yang mana rentang harian yang terendah yang tercatat adalah $18^{\circ} \mathrm{C}$ dan tertinggi $27^{\circ} \mathrm{C}$. Perbedaan suhu $1^{\circ} \mathrm{C}$ hingga $3^{\circ} \mathrm{C}$ per harinya yang terjadi secara tak menentu diakibatkan cuaca dan iklim daerah pegunungan yang dapat berubah-ubah setiap waktunya. Selama observasi, pada beberapa kesempatan Desa Pandansari mengalami kondisi cuaca yang cenderung berawan hingga hujan, sehingga suasana suhu desa menjadi lebih dingin. Sehingga terjadi penurunan suhu $-1{ }^{\circ} \mathrm{C}$ hingga $-2{ }^{\circ} \mathrm{C}$ pada track-record suhu harian dan waktu.

Dari pengamatan yang telah dilakukan, grafik diatas membuktikan bahwa suhu pada Desa Pandansari berpola cenderung sama dari hari ke hari namun menduduki titik capaian yang bervariasi di waktu yang bersamaan, yang mana jika diamati kecenderungan suhu berderajat terendah paling dapat dirasakan pada dini hari menjelang shubuh hingga

PAWON: Jurnal Arsitektur, Nomor 01 Volume II, Bulan Januari-Juni Tahun 2018, ISSN 2597-7636 
terbit matahari, yang mana semakin berjalannya waktu suhu lingkungan mulai merambat naik hingga titik tertinggi di tengah hari. Kemudian suhu akan perlahan menurun setelah melewati tengah hari dan terus menurun hingga malam hari. Pola tersebut akan terus berulang, menciptakan siklus yang akan terus berputar. Sehingga, pola suhu yang terbentuk mendorong masyarakat desa tersebut untuk beradaptasi dengan kondisi suhu sekitar. Tabel perubahan suhu pada lokasi penelitian sebagai berikut :

\begin{tabular}{|c|c|c|c|c|c|c|c|c|}
\hline \multirow[b]{2}{*}{ NO } & \multirow[b]{2}{*}{ HARI } & \multirow[b]{2}{*}{ TANGGAL } & \multicolumn{5}{|c|}{ CAPAIAN SUHU PER WAKTU } & \multirow[b]{2}{*}{ KET. } \\
\hline & & & $\begin{array}{c}03.00- \\
06.00\end{array}$ & $\begin{array}{l}07.00- \\
10.00\end{array}$ & $\begin{array}{l}11.00 \\
14.00\end{array}$ & $\begin{array}{l}15.00 \\
18.00\end{array}$ & $\begin{array}{l}19.00 \\
22.00\end{array}$ & \\
\hline 1 & JUMAT & $\begin{array}{c}05 \text { Mei } \\
2017\end{array}$ & $18^{\circ} \mathrm{C}$ & $21^{\circ} \mathrm{C}$ & $26^{\circ} \mathrm{C}$ & $23^{\circ} \mathrm{C}$ & $20^{\circ} \mathrm{C}$ & \multirow{7}{*}{$\begin{array}{l}\text { Pengukuran } \\
\text { dilakukan } \\
\text { dengan } \\
\text { memakai alat } \\
\text { ukur } \\
\text { konvensional } \\
\text { dan } \\
\text { handphone }\end{array}$} \\
\hline 2 & SABTU & $\begin{array}{c}06 \text { Mei } \\
2017\end{array}$ & $19^{\circ} \mathrm{C}$ & $21^{\circ} \mathrm{C}$ & $26^{\circ} \mathrm{C}$ & $22^{\circ} \mathrm{C}$ & $19^{\circ} \mathrm{C}$ & \\
\hline 3 & MINGGU & $\begin{array}{c}07 \mathrm{Mei} \\
2017\end{array}$ & $18^{\circ} \mathrm{C}$ & $20^{\circ} \mathrm{C}$ & $27^{\circ} \mathrm{C}$ & $24^{\circ} \mathrm{C}$ & $20^{\circ} \mathrm{C}$ & \\
\hline 4 & SENIN & $\begin{array}{c}08 \mathrm{Mei} \\
2017\end{array}$ & $18^{\circ} \mathrm{C}$ & $21^{\circ} \mathrm{C}$ & $26^{\circ} \mathrm{C}$ & $23^{\circ} \mathrm{C}$ & $20^{\circ} \mathrm{C}$ & \\
\hline 5 & SELASA & $\begin{array}{c}09 \mathrm{Mei} \\
2017\end{array}$ & $19^{\circ} \mathrm{C}$ & $20^{\circ} \mathrm{C}$ & $24^{\circ} \mathrm{C}$ & $23^{\circ} \mathrm{C}$ & $21^{\circ} \mathrm{C}$ & \\
\hline 6 & RABU & $\begin{array}{c}10 \mathrm{Mei} \\
2017\end{array}$ & $19^{\circ} \mathrm{C}$ & $20^{\circ} \mathrm{C}$ & $26^{\circ} \mathrm{C}$ & $24^{\circ} \mathrm{C}$ & $21^{\circ} \mathrm{C}$ & \\
\hline 7 & KAMIS & $\begin{array}{c}11 \mathrm{Mei} \\
2017\end{array}$ & $19^{\circ} \mathrm{C}$ & $20^{\circ} \mathrm{C}$ & $26^{\circ} \mathrm{C}$ & $23^{\circ} \mathrm{C}$ & $21^{\circ} \mathrm{C}$ & \\
\hline
\end{tabular}

Kenaikan suhu yang terjadi pada bangunan diharapkan dapat mempengaruhi tingkat kenyamanan penghuni rumah jika cuaca di lingkungan luar sedang dingin. Dapat kita amati jika posisi pawon yang menjadi satu atap dengan bangunan utama (garis orange) memiliki tingkat suhu bangunan tertinggi. Hal tersebut diakibatkan oleh sebaran udara panas dari pawon yang langsung menyebar menuju ruang lain didalam rumah tersebut tanpa adanya elemen pemutus pola sebaran seperti sirkulasi udara yang besar, lubang-lubang sirkulasi disekitar pawon, dimensi ruang dan sebagainya. Sehingga pengaruh suhu yang terjadi juga tidak lepas dari bentuk fisik dan spesifikasi bahan rumah itu sendiri. Sehingga kondisi fisik bangunan juga ikut berperan dalam menaikan suhu bangunan. Maka dari itu jika kita berkunjung pada rumah-rumah warga pada jam-jam dimana aktivitas pawon sedang tinggi seperti pada pagi hari-siang hari, hawa panas dapat dirasakan hingga ruang tamu. Hawa panas yang kita rasakan dapat terus tersimpan dalam rumah jika penggunaan yang terjadi cukup lama atau jika tungku pawon masih menyisakan bara api yang masih menyala saat setelah tungku digunakan. Suhu yang tersimpan tersebut dapat bertahan hingga beberapa jam setelah penggunaan pawon.

Pola sebaran suhu juga dapat kita amati jika posisi pawon terletak semi terpisah dengan bangunan utama. Dengan pola penempatan yang semi terpisah menjadikan pola sebaran dan kenaikan suhu yang terjadi

PAWON: Jurnal Arsitektur, Nomor 01 Volume II, Bulan Januari-Juni Tahun 2018, ISSN 2597-7636 
pada rumah tidak bekerja secara maksimal. Hal tersbut terjadi karena adanya jarak antara pawon dengan bangunan utama sehingga mengurangi pola sebaran suhu yang dihasilkan ketika pawon sedang beroperasi. Peningkatan suhu yang kurang terlihat diakibatkan oleh tungku pawon yang cenderung terlalu jauh dari posisi bangunan utama, terdapat elemen yang mempercepat pergantian antara udara panas dan udara dingin, seperti jendela, pintu, dan semua hal yang terkait dengan elemen fisik pada bangunan maupun elemen non-fisik seperti angin dsb.

\subsection{Aktivitas Angin}

Desa Pandansari yang terletak tepat di kaki Gunung Semeru, memilki kecepatan angin rata-rata yakni 10,5 km/jam ( BMKG Karang Ploso, 2016 ). Hasil dari observasi selama satu minggu menyatakan bahwa aktivitas angin menunjukan titik tiupan terendah mencapai $3 \mathrm{~km} / \mathrm{jam}$ dan tertinggi mencapai $18 \mathrm{~km} / \mathrm{jam}$.

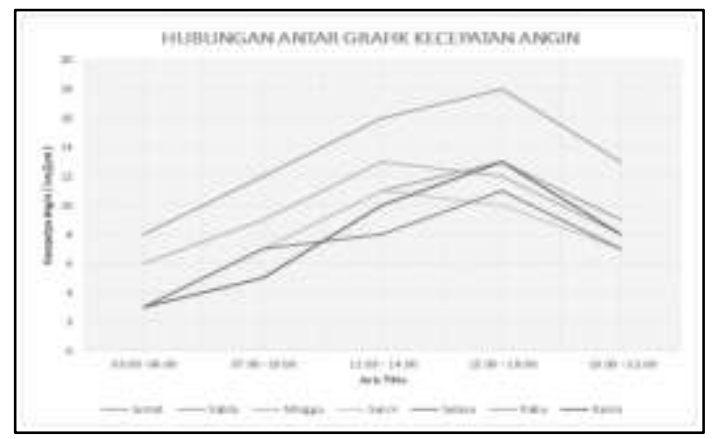

Gambar 3. Diagram Kecepatan Angin

Aktivitas angin lembah sudah dapat diperhatikan berhembus menuju puncak gunung maupun pegunungan pada pukul 07.00 hingga pada puncaknya yaitu siang hari menjelang sore hari pada pukul 15.00. Pada jamjam tersebut hembusan angin didaerah kaki gunung hingga lembah berhembus sehingga kita dapat merasakannya sebagai angin berkekuatan sedang hingga sepoi-sepoi. Fenomena angin lembah terjadi karena pada waktu-waktu tersebut puncak-puncak gunung bertekanan rendah (panas), hal tersebut dikarenakan puncak-puncak gunung terlebih dahulu mendapatkan sinar matahari dibandingkan dengan wilayah-wilayah di kaki gunung maupun lembah yang masih bertekanan tinggi (dingin). Karena perbedaan tersebut maka terjadilah fenomena angin lembah.

Angin gunung, mulai dapat terlihat aktivitasnya pada sore hari selepas pukul 15.00 hingga fajar 06.00. Desa Pandansari pada jam-jam tersebut 
tidak akan mendapatkan hembusan angin yang begitu kencang. Karena konsentrasi kekuatan angin berada pada puncak gunung maupun pegunungan. Hal tersebut dikarenakan, menjelang malam hari puncak gunung maupun pegunungan relatif cepat melepaskan radiasi matahari dibandingkan kaki gunung maupun lembah. Sehingga puncak gunung bertekanan relatif tinggi (dingin) jika dibandingkan dengan wilayah lembah maupun kaki gunung. Sehingga berhembuslah angin dari puncak gunung menuju kaki gunung atau lembah.

Akibat dari posisi pawon yang cenderung terpisah dari bangunan utama menjadikan kenaikan suhu yang diharapakan ketika pawon beroperasi kurang dapat dirasakan. Perubahan suhu yang didapatkan jika kita amati pada pola grafik suhu, pada pawon dengan letak semi terpisah, memilki posisi garis yang hampir berhimpitan dengan Suhu Lingkungan (To) sehingga dapat disimpulkan jika pawon dengan posisi yang semi terpisah kurang dapat meningkatkan suhu pada bangunan, walaupun terlihat sedikit sekali penginkatan yang terjadi, hal tersbut juga tidak lepas dari faktor-faktor lain seperti kondisi fisik bangunan, cuaca dan iklim, dan faktor-faktor lainnya yang ikut berperan dalam meningkatkan suhu bangunan. Keadaan pawon ketika beroperasi yang tidak mempengaruhi sama sekali kenaikan suhu pada bangunan juga terjadi pada pawon dengan posisi yang terpisah. Hal tersebut bahkan tidak berpengaruh sama sekali pada suhu bangunan hingga pada saat pawon sedang dalam tingkat aktivitas yang berat.

\section{KESIMPULAN}

Letak posisi pawon pada bangunan sangat berpengaruh sekali terhadap capaian suhu yang diharapkan dapat memberi kenyamanan pada saat suhu lingkungan luar sedang dingin. Selain itu elemen-elemen bangunan, tingkatan operasional harian pawon, dan faktor alam juga dapat mempengaruhi luaran suhu yang dihasilkan oleh tungku.

\section{DAFTAR PUSTAKA}

Dewi, Pancawati. 2010. Peran Perapian Dalam Rumah Tinggal Masyarakat Tengger.

Evans, Martin. 1980. Housing, Climate and Comfort. The Architectural Press. London.

Givoni, B. 1998. Climate Considerations in Building and Urban Design. Van Nostrand Reinhold. New York.

Sasongko, Ibnu. 2005. Pembentukan Struktur Ruang Permukiman Berbasis Budaya (Studi Kasus: Desa Puyung - Lombok Tengah). Universitas Kristen Petra Surabaya 